\title{
Estilos de Vida Saludable Política Pública en Proceso
}

Marc Lalonde en 1974, propuso un modelo explicativo de los determinantes de salud, que se utiliza en la actualidad, en el que se reconoce al estilo de vida, así como el ambiente incluyendo el social, en el sentido amplio junto a la biología humana y la organización de los servicios de salud. Para caracterizar el modo de vida como determinante de salud, se han utilizado múltiples criterios en los que la epidemiología y las ciencias sociales han hecho grandes aportes al establecer relaciones entre las condiciones materiales y la forma en que los grandes grupos sociales se organizan y se realizan productivamente en esas condiciones. Ejemplos varios como servicios de salud y su utilización, instituciones educacionales y nivel educacional de la población, tipos de viviendas, condiciones y hacinamiento, abasto de agua e higiene ambiental, etc. Esta categoría resulta imprescindible en la comprensión no sólo del estado de salud de una población sino, además, en la confección de políticas sanitarias y estrategias de promoción de salud, ya que su campo abarca los grandes grupos sociales en su conjunto.

La prevención de la enfermedad y promoción de la salud son dos temas de alta prioridad en las políticas públicas y acciones de salud pública en los países del mundo actual, las mismas que deben de ser liderados por los Ministerios de Salud Pública. Indudablemente la conducta de las personas esté directamente relacionada con estos temas. El tiempo de sueño, los hábitos alimentarios, el manejo de la alimentación y el peso corporal, la recreación, la actividad física, la abstención o consumo de alcohol, de tabaco y de drogas recreativas, el uso de cinturón de seguridad, el uso de casco cuando se utiliza bicicleta y motocicleta, el cumplimiento de las normas de tránsito, el sexo seguro y protegido, el cepillado de dientes, la vacunación, la adopción de medidas de tamizaje para la detección temprana de enfermedades, entre otros comportamientos, hacen a las personas más o menos propensas a la enfermedad o a mantener sus estados de salud (1). Por tanto, intervenir los estilos de vida se convierte en una de las acciones más eficaces para la prevención de la enfermedad y la promoción de la salud (2), de tal forma que cada vez es más frecuente que los médicos recomienden a sus pacientes la modificación de ciertas conductas que atentan contra su salud. Sin embargo la paradoja más grande es que los mismos profesionales de la salud quienes presentan estilos de vida inadecuados. Se supone que al tener pleno conocimiento de la relación entre comportamiento y salud, así como de la etiología de las enfermedades y su tratamiento, se trataría de personas que evitarían conductas que atentan contra la salud. Sin embargo no siempre es así, siendo frecuente encontrar médicos fumadores, bebedores, sedentarios, obesos, etc. Al parecer, para algunos de ellos no es un problema recomendar hábitos de vida saludable que ellos mismos no ponen en práctica.

Al respecto, hay evidencias $(3,4)$ que demuestran que los médicos que cuidan su salud y practican estilos de vida saludables, tienen mayor probabilidad de recomendar y de inducir en sus pacientes hábitos igualmente saludables y de tener mayor éxito en el seguimiento de sus recomendaciones, contrario a aquellos de hábitos no saludables, que tienden a practicar una medicina curativa en lugar de preventiva y que probablemente son poco escuchados por sus pacientes cuando les recomiendan comportamientos que evidentemente, ellos tampoco practican. La categoría estilos de vida se trata de un término que atañe a pautas comportamentales, es decir, a formas recurrentes de comportamiento que se ejecutan de forma estructurada y que cuando se constituyen en el modo habitual de responder ante una situación se pueden entender como hábito, permitiendo entender la relación directa que se establece entre la forma y el estilo de vivir con aspectos de la salud (5).

El autocontrol del comportamiento constituye la más importante herramienta de la que puede disponer un individuo para realizar cambios en su estilo de vida; y dado que el estilo de vida está determinado por las condiciones de vida, un elemento importante en esta investigación es la identificación de los factores de riesgo. Aspectos como factores motivacionales, el aprendizaje, las creencias y las influencias sociales, además de la historia biológica, han sido identificados como componentes de las conductas y hábitos que caracterizan el estilo de vida de una persona, por lo tanto, establecer conductas saludables y eliminar conductas de riesgo de manera estable, como aspiración de la promoción de salud, constituye un reto para la investigación científica y la generación de evidencia científica de la cual forma parte nuestra revista científica Agora. 


\section{REFERENCIAS BIBLIOGRÁFICAS}

1. Díaz-Llanes G. El comportamiento en psicología de la salud. En: HernándezMeléndez E, Grau-Abalo J, editors. Psicologia de la Salud: fundamentos y aplicaciones.Mexico: Universidad de Guadalajara; 2005. p 179-99.

2. Smith TW, Orleans CT. Prevention and Health Promotion: Decades of Progress, New Challenges, and an Emerging Agenda. Health Psychology. 2004;23(2): 126-31.

3. Frank E, Rothenberg R, Lewis $\mathrm{Ch}$, Belodoff BF. Correlates of Physcian Prevention-Related Practices. Findings From the Women Physians' Health Study. Archves of Family Medicine. 2000;9:
4. Frank E, Biola H, Burnett C. Mortality rates and causes among U.S. physicians. Journal of the American medical association. 2000;19(3): 155-9.

5. Rodriguez-Marin J. Psicología Social de la Salud. Madrid, España: Editorial Síntesis S.A.; 1995.

Dr. Walter Gómez ${ }^{1, a}$

\footnotetext{
${ }^{1}$ Oficina de Investigación y Creatividad Intelectual - Universidad María Auxiliadora- Lima- Perú

${ }^{a}$ Editor Jefe - AGORA Revista Científica
} 